\title{
PEMBELAJARAN LINTAS BUDAYA DALAM MENANAMKAN NILAI SOSIAL BAGI MAHASISWA UIN MAULANA MALIK IBRAHIM MALANG
}

\author{
Samsul Susilawati, Nikmatuzzuhro, Siti Annijat Maimunah \\ Fakultas Ilmu Tarbiyah dan Keguruan (FITK) UIN Maulana Malik Ibrahim Malang \\ *Corresponding author: susilawati@pips.uin-malang.ac.id
}

\begin{abstract}
Abstrak
Pembelajaran Lintas Budaya (PLB) merupakan proses belajar mengajar yang melatihpembelajar pada masa depan untuk menghilangkan pembatas antara belajar dalam kelas, dan kehidupan nyata dalam masyarakat antara sains modern dan pengetahuan tradisonal dan terutama antara generasi muda dengan warisan budaya yang ada. Obyek penelitian adalah mahasiswa asing UIN Maulana Malik Ibrahim Malang.Pembelajaran lintas budaya adalah pembelajaran budaya local jenius kepada mahasiswa asing. Budaya merupakan kepaduan pengetahuan, kepercayaan dan perilaku manusia yang sangat bergantung pada kemampuan mereka dalam belajar dan memberikannya kepada generasi penerusnya tentang pengetahuan yang dimilikinya. Dalam mentransfer pengetahuan budaya yang dimiliki dapat dilakukan melalui komunikasi sosial yang menggunakan sarana bahasa. Selain itu, untuk memadukan sistem pengetahuan dan kepercayaan sebagai dasar perilaku budaya, dapat melalui bagaimana pola berbahasanya.
\end{abstract}

Keywords: Pembelajaran; masyarakat;budaya; pengethuan 



\section{INTRODUCTION}

Urgensi pembelajaran lintas budaya dalam pembelajaran utamanya bagi pengajar dan pembelajar bahasa. Bagi mahasiswa dan pengajar di wilayah Asia, mereka tidak banyak mengalami kesulitan, karena masing-masing budaya di antara negara-negara yang ada di ASEAN memiliki banyak kesamaan. Misalnya pembelajar Thailand dan Jepang serta Malaysia tidak banyak kendala untuk belajar Bahasa Indonesia. Mereka masih dalam lingkup budaya yang hampir sama. Dalam Bahasa Thai dan Bahasa Indonesia, banyak kosa kata yang berasal dari Bahasa Sansekerta. Jadi, masih ada kesamaan bidang fonologi, sintaksis, dan budaya antara Bahasa Thai dan Bahasa Indonesia. Hal itulah yang mempermudah komunikasi di antara mereka. Sedangkan di UIN Maliki Malang dan Universitas Negeri Jakarta tidak hanya berasal dari Asean saja melainkan dari luar Asean misalnya yang berada di UIN Maliki Malang; Cina, Somalia, Kamboja, Srilangka, Irak, Saudi Arabiyah, Rusia dst, semua beragama Islam.di Universitas Negeri Jakarta sama dengan UIN Maulana Malik Ibrahim Malang dari berbagai manca negara baik Asean maupun Eropa dan memiki agama yang Beragam. Seorang pembelajar tentu memikili. Citacita mereka tentu akan berpengaruh pada nilai-nilai dan sikap mereka dalam hidup bermasyarakat. Contoh: Sikap masyarakat AS, memiliki sikap individualism dan tidak percaya dengan negara lain. Aspek sosial budaya yang berlaku dalam masyarakat berfungsi sebagai pemberi informasi budaya masyarakatnya (Abdul Gaffar Ruskhan, 2007). Adapun aspek budaya yang perlu diketahui oleh seorang pembelajar budaya adalah: - benda-benda budaya, gerak-gerak anggota badan, jarak fisik ketika berkomunikasi, kontak pandang mata dalam berkomunikasi, penyentuhan, adat istiadat yang berlaku dalam masyarakat, sistem nilai yang berlaku dalam masyarakat, sistem religi yang dianut dalam masyarakat, mata pencaharian, kesenian, pemanfaatan waktu, cara berdiri, duduk, dan menghormati orang lain, keramahtamahan, tegur sapa, dan basa-basi, gotong royong, pujian, sopan santun.Fenomena mahasiswa yang tidak mengenal budaya daerah setempat, sering terjadi kesalahpahaman hanya karena tidak mengenal etika budaya setempat. Oleh karena itu berada di sejumlah negara mahasiswa harus mengenal budaya lokal agar dapat bersosial masyarakat yang baik. Sebagaimana apa yang terdapat di dalam tulidan Webster adalah sebagai berikut :"Culture (is) the integrated pattern of human knowledge, belief, and behavior that depends upon man's capacity for learning and transmitting knowledge to succeeding generations (Webster, 1989:314).Budaya merupakan kepaduan pengetahuan, kepercayaan dan perilaku manusia yang sangat bergantung pada kemampuan mereka dalam belajar dan memberikannya kepada generasi penerusnya tentang pengetahuan yang dimilikinya. Dalam mentransfer pengetahuan budaya yang dimiliki biasanya dapat dilakukan melalui komunikasi sosial yang menggunakan sarana bahasa. Selain itu, untuk memadukan sistem pengetahuan dan kepercayaan sebagai dasar perilaku budaya, juga dapat melalui bagaimana pola berbahasanya. Oleh karena itu, "verbalisasi lintas budaya" sangat penting. Konsep verbalisasi lintas budaya merupakan sebuah konsep yang universal yang terungkap secara verbal dan berbeda karena konveksi budaya yang berbeda pula antar negara yang satu dengan negara lainnya, atau daerah yang satu dengan daerah lainnya. Sedangkan dalam konsep lokal budaya sebuah daerah memiliki kekhasan sesuai dengan bahasa lokalnya. Contoh: tentang ucapan selamat, Dalam budaya muslim, mengucapkan "Marhaban yaa Ramadhan" tidak diucapkan oleh penutur Bahasa Arab (masyarakat Saudi Arabia), melainkan masyarakat Indonesia atau yang lainnya juga menggunakan kata 
ungkapan tersebut. Contoh lain, misalnya konsep warna. Pada perayaan tahun baru Cina yang disebut "Imlek", ucapan di Indonesia dikenal dengan "Gong $\mathrm{Xi} \mathrm{Fa}$ Cai" yang artinya "semoga rejeki selalu datang melimpah". Perayaan diadakan dengan memasang dekorasi dengan warna dominan merah. Warna merah dimaknai dengan "kesejahteraan dan kebahagiaan". Warna tersebut juga digunakan dalam kostum Cina. Sedangkan, makna merah lokal daerah lain berbeda makna. Indonesia lambang merah putih, kata merah berarti berani. Sedangkan di warung-warung yang terpasang lampu/lampion warna merah pertanda di situ tempat pelacuran.

Urgensi pembelajaran lintas budaya dalam pembelajaran utamanya bagi pengajar dan pembelajar bahasa. Bagi mahasiswa dan pengajar di wilayah Asia, mereka tidak banyak mengalami kesulitan, karena masing-masing budaya di antara negara-negara yang ada di ASEAN memiliki banyak kesamaan. Misalnya pembelajar Thailand dan Jepang serta Malaysia tidak banyak kendala untuk belajar Bahasa Indonesia. Mereka masih dalam lingkup budaya yang hampir sama. Dalam Bahasa Thai dan Bahasa Indonesia, banyak kosa kata yang berasal dari Bahasa Sansekerta. Jadi, masih ada kesamaan bidang fonologi, sintaksis, dan budaya antara Bahasa Thai dan Bahasa Indonesia.

Hal itulah yang mempermudah komunikasi di antara mereka.Seorang pembelajar tentu memiliki cita-cita. Citacita mereka tentu akan berpengaruh pada nilai-nilai dan sikap mereka dalam hidup bermasyarakat. Contoh: Sikap masyarakat AS, memiliki sikap individualism dan tidak percaya dengan negara lain.Aspek sosial budaya yang berlaku dalam masyarakat berfungsi sebagai pemberi informasi budaya masyarakatnya (Abdul Gaffar Ruskhan, 2007). Adapun aspek budaya yang perlu diketahui oleh seorang pembelajar budaya adalah:benda-benda budaya,gerak-gerak anggota badan,jarak fisik ketika berkomunikasi,kontak pandang mata dalam berkomunikasi,penyentuhan, adat istiadat yang berlaku dalam masyarakat,sistem nilai yang berlaku dalam masyarakat,sistem religi yang dianut dalam masyarakat,mata pencaharian,kesenian, pemanfaatan waktu,cara berdiri, duduk, dan menghormati orang lain,keramah-tamahan, tegur sapa, dan basa-basi,gotong royong,pujian,sopan santun.

Fenomena mahasiswa yang tidak mengenal budaya daerah setempat, sering terjadi kesalahpahaman hanya karena tidak mengenal etika budaya setempat. Oleh karena itu berada di sejumlah negara mahasiswa harus mengenal budaya lokal agar dapat bersosial masyarakat yang baik." Culture (is) the integrated pattern of human knowledge, belief, and behavior that depends upon man's capacity for learning and transmitting knowledge to succeeding generations (Webster, 1989:314).

Budaya merupakan kepaduan pengetahuan, kepercayaan dan perilaku manusia yang sangat bergantung pada kemampuan mereka dalam belajar dan memberikannya kepada generasi penerusnya tentang pengetahuan yang dimilikinya. Dalam mentransfer pengetahuan budaya yang dimiliki biasanya dapat dilakukan melalui komunikasi sosial yang menggunakan sarana bahasa.

Sistem pengetahuan dan kepercayaan sebagai dasar perilaku budaya, juga dapat melalui bagaimana pola berbahasanya. Oleh karena itu, "verbalisasi lintas budaya" sangat penting. Konsep verbalisasi lintas budaya merupakan sebuah konsep yang universal yang terungkap secara verbal dan berbeda karena konveksi budaya yang berbeda pula antar negara yang satu dengan negara lainnya, atau daerah yang satu dengan 
daerah lainnya. Sedangkan dalam konsep lokal budaya sebuah daerah memiliki kekhasan sesuai dengan bahasa lokalnya.Contoh: tentang ucapan selamat. Dalam budaya muslim, mengucapkan "Marhaban yaa Ramadhan" tidak diucapkan oleh penutur Bahasa Arab (masyarakat Saudi Arabia), melainkan masyarakat Indonesia atau yang lainnya juga menggunakan kata ungkapan tersebut.Contoh lain, misalnya konsep warna.Pada perayaan tahun baru Cina yang disebut "Imlek", ucapan di Indonesia dikenal dengan "Gong Xi Fa Cai" yang artinya "semoga rejeki selalu datang melimpah".

Perayaan diadakan dengan memasang dekorasi dengan warna dominan merah. Warna merah dimaknai dengan "kesejahteraan dan kebahagiaan". Warna tersebut juga digunakan dalam kostum Cina. Sedangkan, makna merah lokal daerah lain berbeda makna. Indonesia lambang merah putih, kata merah berarti berani. Sedangkan di warung-warung yang terpasang lampu/lampion warna merah pertanda di situ tempat pelacuran.

\section{PEMBAHASAN}

A. Pembelajaran Linas Budaya

Proses belajar mengajar diawali dengan menentukan dan merumuskan masalah, mengumpulkan data dan informasi, mengkaji latar belakang dan penyebabnya, mencari peraturan yang berhubungan, mengkaji kebijakan publik yang berlaku, meneliti bagaimana sikap terhadap masalah itu, dan mencari berbagai alternatif solusi.

KKNI merupakan salah satu langkah untuk mewujudkan mutu dan jati diri bangsa Indonesia dalam sektor sumber daya manusia yang dikaitkan dengan program pengembangan sistem pendidikan dan pelatihan secara nasional. Setiap tingkat kualifikasi yang dicakup dalam KKNI memiliki makna dan kesetaraan dengan capaian pembelajaran yang dimiliki setiap insan pekerja Indonesia dalam menciptakan hasil karya dan kontribusi yang bermutu di bidang pekerjaan masing-masing. Kebutuhan Indonesia untuk segera memiliki KKNI sudah sangat mendesak mengingat tantangan dan persaingan global pasar tenaga kerja nasional maupun Internasional yang semakin terbuka. Pergerakan tenaga kerja dari dan ke Indonesia tidak lagi dapat sistem dibendung dengan peraturan atau regulasi yang bersifat protektif.

Ratifikasi yang telah dilakukan Indonesia untuk berbagai konvensi regional maupun internasional, secara nyata menempatkan Indonesia merupakan sebuah negara yang semakin terbuka dan mudah tersusupi oleh kekuatan asing melalui berbagai sektor termasuk sektor perekonomian, pendidikan dan pelatihan dan lain-lain. Oleh karena itu, persaingan global tidak lagi terjadi pada ranah internasional akan tetapi sudah nyata berada pada ranah nasional. Upaya yang dapat dilakukan untuk mengantisipasi tantangan globalisasi pada sektor ketenagakerjaan adalah meningkatnya ketahanan sistem pendidikan dan pelatihan secara nasional dengan berbagai cara antara lain:

- Meningkatkan mutu pendidikan dan pelatihan.

- Mengembangkan sistem kesetaraan kualifikasi antara capaian pembelajaran yang diperoleh melalui pendidikan dan pelatihan, pengalaman kerja maupun pengalaman mandiri dengan kriteria kompetensi yang dipersyaratkan oleh suatu jenis bidang dan tingkat pekerjaan.

- Meningkatkan kerja sama dengan pengakuan timbal balik yang saling menguntungkan antara institusi penghasil dengan pengguna tenaga kerja.

- Meningkatkan pengakuan dan kesetraan Kualifikasi ketenagakerjaan Indonesia dengan negara-negara lain di dunia baik 
terhadap capaian pembelajaran yang telah ditetapkan oleh institusi pendidikan dan pelatihan maupun kriteria kompetensi yang dipersaratkan untuk suatu bidang dan tingkat pekerjaan tertentu.

- Secara mendasar langkah-langkah pengembangan tersebut meliputi permasalahan yang bersifat multi aspek dan keberhasilannya sangat tergantung dari sinergi dan peran proaktif dari berbagai pihak yang terkait dengan peningkatan mutu sumber daya manusia nasional termasuk pemerintah, asosiasi profesi, asosiasi industri, institusi pendidikan dan pelatihan, serta masyarakat luas.

Secara umum, kondisi awal yang dibutuhkan untuk dapat melaksanakan suatu program penyetaraan kualifikasi ketenagakerjaan tersebut tampak belum cukup kondusif dalam beberapa hal seperti misalnya belum meratanya kesadaran mutuh di kalangan institusi penghasil kerja, belum tumbuhnya kesadaran tentang pentingnya kesetaraan kualifikasi antara capaian pembelajaran yang dihasilkan oleh penghasil tenaga kerja dengan deskripsi keilmuan, keahlian dan keterampilan yang dibutuhkan di bidang kerja atau profesi yang termasuk terbatasnya pemahaman mengenai dinamika tantangan sektor tenaga kerja di tingkat dunia. Oleh karena itu, upaya-upaya untuk mencapai keselarasan mutu dan penjejangan kualifikasi kelulusan dari institusi pendidikan formal dan nonformal, dengan deskripsi kompetensi kerja yang diharapkkan oleh pengguna lulusan perlu diwujudkan dengan segera. Di Jalur pendidikan nonformal, pada bulan Mei 2016 terccatat sekkitar 19.692 lembaga kursus dan pelatihan yang menyelengggarakan pendidikan nonformal dalam bentuk beragam jenis kursus dan pelatihan (sumber: www.infokursus.net) di bawah pembinaan Kementerian
Pendidikan dan Kebudayaan. Salah satu infrastruktur yang penting dalam menncapai keselarasan mutu dan penjejangan kualifikasi antara lulusan dari institusi penyelenggara kursus dan pelatihan dengan deskripsi kompetensi kerja yang diharapkan oleh pengguna lulusan adalah Standar Kompetensi Lulusan atau disingkat SKL.

Salah satu bidang yang mengembangkan Standar Kompetensi Lulusan ini adalah Bidang Bahassa Indonesia bagi Penutur Asing (BIPA). Ada perbedaan antara BIPA dengan bidang lainnya, yaitu peserta yang mengikuti kursus dan pelatihan ini adalah peserta yang merupakan warga negara asing atau warga negara Indonesia yang tidak bisa berbahasa Indonesia. Peserta didik ini mempelajari Bahasa Indonesia untuk berbagai tujuan, diantaranya dapat berinteraksi dan berkomunikasi dengan menggunakan bahasa Indonesia, bukan untuk mendapatkan keahlian dalam bidang pekerjaan. Penyusunan kompetensi lulusan kursus dan pelatihan untuk bidang Bahasa Indonesia bagi penutur Asing (BIPA) ini diadaptasi dari CEFR dan penjejangan mengikuti penjejanga daam uji adaKemahiran berbahasa Indonesia yang dikembangkan oleh Pembinaan dan Pengembangan Bahasa. Alasannya adalah sebagai berikut:

- UKBI merupakan uji kemahiran berbahasa Indonesia yang terstandar yang dirilis oleh Badan Pengembangan dan Pembinaan bahasa dan telah digunakan untuk menguji kemahiran berbahasa Indonesia baik orang Indonesia maupun orang asing.

CEFR merupakan kerangka acuan bahasa asing di wilayah Eropa. Bahasa Indonesia d setiapalam konteks kursus ini setara dengan bahasa Indonesia sebagai bahasa Asing. Untuk itu CEFR dianggap relevan untuk dijadikan rujukan dalam penentuan kompetensi setiap level dalam bidang bahasa. 


\section{METODE PENELITIAN}

Jenis penelitian ini merupakan bentuk penelitian kualitatif. Data dan informasi yang telah dikumpulkan akan didiskusikan dengan teori yang relevan. Selanjutnya dikaji dengan teori-teori yang dirujuk baik melalui sumber pustaka maupun jurnal ilmiah yang mutakhir mengenai hegemoni budaya negara yang berkaitan dengan nilai moral dan karakter akhlak mulia., Penentuan latar penelitian, Mahasiswa UIN Malang dan Universitas Negeri Jakarta sangat perlu diberikan materi perkuliahan lintas budaya. Sebab di kampus ini mahasiswa yang belajar meliputi mahasiswa yang berasal dari beberapa negara. Tujuan pembelajaran lintas budaya agar mereka dapat bersosialisasi dengan baik. Tidak akan terjadi salah paham di antara mereka karena latar budaya yang berbeda dan bahasa yang berbeda. Oleh karena itu urgensi materi lintas budaya diharapkan dapat membimbing mereka dalam bersosialisasi baik di Mahad atau di kampus. Adapun pemilihan latar belakang ini diharapkan dapat memberikan kelancaran peneliti dan informan untuk saling bertemu dan berdiskusi, Adapun Pelaksanaan pengumpulan data, Agar pengumpulan data dan informasi dapat berjalan lebih efektif dan efisien maka pengumpulan data di lapangan akan diatur dengan stategi berikut; Pertama, pengamatan/observasi terhadap manifestasi kebudayaan mahasiswa BIPA dan mahasiswa UIN reguler (berasal dari Indonesia) dilakukan penelusuran konteks latar perilaku mereka melalui konteks formal atau informal terhadap informan.dan mahasiswa matrikulasi dan mahasiswa Universitas Negeri Jakarta Seperti konteks mereka bertegur sapa sesama teman seasal negara atau dengan teman yang berasal dari negara lain. Dengan mengamati perilaku dan interaksi sosial mereka diharapkan dapat memperoleh informasi dan data tentang budaya asal mereka dan budaya lokal terteliti.Kedua, pelibatan pada kegiatan sosial dan keagamaan serta kegiatan sehari-hari/bersantai. Misalnya shalat berjamaah, makan bersama, jalan-jalan bersama. Kegiatan ini dimaksudkan untuk menjalin keakraban dengan informan atau nara sumber. Hal tersebut untuk memperoleh pengetahuan yang memadai tentang aspek-aspek sosial mereka dan kebudayaannya yang meliputi: struktur sosial, interaksi, skenario, dan konstruksi sosialnya. Selain itu, untuk memperoleh data lain tentang mereka, penulis menggunakan teknik dokumentasi, baik dokumen akademin atau dokumen lain yang dimiliki oleh pengajar (dosen),Ketiga, pelibatan dari peneliti sebagai pengajar atau tutor dalam kegiatan-kegiatan belajar mereka. Peneliti dibantu oleh seorang asisten yang mencatat dan merekam kegiatan mulai dari awal hingga akhir.

Teknik pengumpulan data ini akan memperoleh data dan informasi tentang hegemoni negara dan kepemimpinan intelektual, moral, ideologi, serta catatan perilaku terteliti, Pelaksanaan pengumpulan data dan informasi tersebut memang memerlukan waktu yang lama kurang lebih 1 semester. Pengumpulan data awal sudah dimulai oleh peneliti sebagai prapenelitian sejak awal semester I 2017-2018 sampai pertengahan Bulan Desember 2017. Dan untuk melengkapi data selanjutnya, peneliti hadir dalam kegiatan BIPA atau di kelas reguler mahasiswa asing di kelas seminggu sekali di semester 2 2017-2018, Teknis analisis data; Informasi dari data yang berhasil dikumpulkan dari lapangan dianalisis melalui beberapa teknik analisis sesuai dengan jenis data, yaitu: 1). Teknis kajian etnografi, 2) analisis riwayat hidup, 3) dan teknik analisis isi. Kajian etnografi digunakan untuk memahami aktifitas budaya mahasiswa asing, dan perubahan budaya yang terjadi, sehingga analisis ini akan ditemukan hegemoni tingkat lokal. Sedangkan analisis riwayat hidup 
digunakan untuk menganalisis pengalaman informan. Selanjutnya, analisis isi untuk mengkaji pembelajaran lintas budaya di kelas Perguruan Tinggi.Analisa data akan dilakukan secara terus-menerus selama pengumpulan data berlangsung selama waktu penelitian. Data informasi yang berasal dari pengamatan, wawancara mendalam, catatan lapangan, dan rekaman dipilah-pilah dan dikategorikan tertentu sesuai dengan budaya-budaya yang dibawa dari masing-masing negara sesuai dengan penekanan intelktual, nilai moral, dan karakteristik akhlak mulia.

Informasi dan data yang diperoleh dari lapangan yang dikaji dengan menggunakan pendekatan kualitatif. Data dan informasi didiskusikan dengan teori yang relevan terutama yang didukung dengan jurnal-jurnal yang mutakhir yang membahas tentang lintas budaya. Dengan demikian akan tampak potensi kontribusi teoritis yang dihasilkan oleh penelitian ini.Trianggulasi dengan teman sejawat dan pakar kebudayaan terhadap hasil sementara penelitian dilakukan secara terus-menerus. Keterujian empiris terbuka kemungkinan diskusi bukan berdebat. Recheck dan cross-check informasi data dari lapangan digunakan untuk memahami kompleksitas fenomena sosial ke sebuah esensi yang sangat sederhana.

\section{PENUTUP}

Proses Pembelajaran Lintas

Budaya bagi mahasiswa Asing Dalam Penanaman nilai-nilai moral dan Sosial salah satunya melalui pengajaran Bahasa Indonesia bagi Penutur Asing (BIPA). Penelitian Bahasa menjadi bagian penting untuk diteliti karena penggunanya. Beberapa penelitian terkait dengan BIPA sampai saat ini hanya berkaitan dengan pengajaran BIPA saja, hanya sekitar pembelajaran berbahasa baik bahasa tulis ataupun lisan saja. Ada Beberapa Penelitian terkait dengan BIPA antara lain Rifca Farih Azizah, Widodo Hs, dan Ida
Lestari dari Universitas Negeri Malang yaitu bentuk pembelajaran BIPA, sedangkan Penelitian yang akan dilaksanakan ini adalah penerapan penanaman nilai -nilai untuk mahasiswa BIPA. Persamaannya adalah proses pembelajaran mahasiswa BIPA. Perbedaanya adalah pada penelitian yang dilakukan Pembelajaran BIPA sebagai alat untuk Proses pembelajaran Lintas Budaya bagi mahasiswa Asing. Dan adanya bentuk kerjasama antara peneliti dengan mahasiswa Asing.

Dari persamaan dan perbedaan kajian penelitian ddari artikel yang pernah dilakukan ini menjadi rujukan tersendiri untuk menampilkan sisi keaslihan penelitian. Penelitian ini lebih lebih memfokuskan pada penerapana pembelajaran lintas budaya bagi mahasiswa Asing dalam penanaman nilainilai mora dan sosial sebagai masyarakat berkarakter Akhlaq mulia. Mahasiswa Internasionalbaik yang akanbelajar di UIN Maliki Malang, maupun yang sudah menjadi mahasiswa UIN Maliki Malang serta mahasiswa Internasional Universitas Negeri Jakarta. Oleh karena itu menjadi bagian penting untuk dikaji dalam proses pembelajaran budaya yang berbeda.

Penelitian ini dilakukan pada Perguruan Tinggi UIN Malang pada mahasiswa BIPA yang berasal dari negara Thailand, Sudan, Libya, Rusia, Kamboja, Malaysia, Yaman, Saudi Arabia, Timor Leste, Cina, Madagaskar, Nigeria, dan Indonesia. Adapun mereka yang menjadi informan belajar di Fakultas Saintek, Psikologi, Farmasi, Syariah, Tarbiyah, dan Ekonomi.

\section{DAFTAR PUSTAKA}

$$
\begin{aligned}
& \text { Agustiar Syah Nur, } 2002 \\
& \text { PerbandinganSistemPendidik } \\
& \text { an, LubukAgung, Bandung. }
\end{aligned}
$$


Azizi, Qodri A, 2003, MelawanGlobalisasi:

Reinterpretasiajaran Islam

Persiapan

SDM

danterciptanyamasyarakatma

dani,

Yogyakarta

:PustakaPelajar

Barry Glassner\&Rosanna Hertz, 1999,

Qualitative Sociology as

Everyday life, Sage

Publication,

Chaney, David dalam Idi Subandy Ibrahim,1996,Lifestyles,Sebu ahPengantarkomprehensif, Jalasutra, Yogyakarta.

Chris Barker, 2000, Cultural Studies TeoridanPraktek,

KreasiWacana, , Yogyakarta.

Denzim,

Norman

$\mathrm{K}$

danYvonnaS.Lincoln, 2009,

Handbook of Qualitative

research, Yogyakarta

:PustakaPelajar.

------------,1994. Handbook

of Qualitatif Research.

London: Sage Publication.

EmadEldin

Shahin,2002,

ModernisasibukanWesternisa

si,MadaniPustaka,

Yogyakarta.

Effendi, B. 2001.Masyarakat Agama danPluralismeKeagamaan.

Yogyakarta: Galang Press.

Fakih, Mansyur,2002, Jalan Lain:

Manifesto

IntelektualOrganik,

Yogyakarta: PustakaPelajar.

FedyaniSaifuddin,Achmad,(2006),

AntropologiKontemporer,Pre nada Media Group, Jakarta.

George Boeree,C,DR,General

Psychology, 2013,

PsikologiKepribadian,

Persepsi, Kognisi,

EmosidanPerilaku, Ar-ruzz

Media, ,Jakarta.
Hari Poerwanto, 2008, Kebudayaan dan Lingkungan Dalam Perspektif Antropologi, PustakaPelajar, Yogyakarta

J.E. Goldthorpe, 1998, Sosiologi Duniaketiga, Gramedia Pustaka Utama, Jakarta.

Jean P Baudrillard, penerjemahWahyunto, MasyarakatKonsumsi, Kreasi Wacana,2004, Yogyakarta.

Joel M.Charon, Symbolic Interactionism, an intrroduction, an interpretation, an integration, Prentice Hall Series in Sociology.

Kuswarno, Engkus, MS.DR. Prof, 2009, MetodologiPenelitianKomunikasiF enomenologi, WidyaPadjadjaran, Bandung.

Koentjaraningrat. 2000. Kebudayaan, Mentalitasdan Pembangunan. Jakarta: PT GramediaPustakaUtama..

Maliki, Zainuddin, 2004.Narasi Agung: TigaTeoriSosialEgemonik, Surabaya, LPAM

Mary F.Rogers, Barbie Culture, 2003, IkonBudayaKonsumerisme,

PenerbitBentangBudaya, Yogyakarta.

Moleong, Lexy J. 2005.Metodologi Penelitiankualitatif, Bandung: PT. RemajaRosdakaryahal 4-5.

Muhannif, A. (eds.). 2002 PerempuandalamLiteraturKlasik. Jakarta: GramediaPustaka.

Neuman, W.L. 2000. Social Research Methods, Qualitatif and Quantitatif Approaches. Boston: Allyn and Bacon.

Subur ,Alex (2006), Semiotika Komunikasi, Remaja Rosdakarya, Bandung (2006), Review Buku Psikologi Umum, Pustaka Setia.

Supardan Dadang,2009. PengantarilmuSosial,BumiAksara, Jakarta.

Samuel, Hanneman, 2012. Peter L. Berger SebuahPengantarRingkas. Depok: PenerbitKepikhal 45. 
Sanggar Kanto, (2011), PerspektifModernisasidanPerubaha nSosial, 2011 UB Press Malang.

SarlitoW.Sarwono, danEkoA.Meinarno, (2011),PsikologiSosial,PT.Salemba Humanika, Jakarta.

Syaparuddin, S., \& Elihami, E. (2020). PENINGKATAN KECERDASAN EMOSIONAL (EQ) DAN KECERDASAN SPIRITUAL (SQ) SISWA SEKOLAH DASAR SD NEGERI 4 BILOKKA SEBAGAI UPAYA MENINGKATKAN KUALITAS DIRI DALAM PROSES PEMBELAJARAN PKn. Mahaguru: Jurnal Pendidikan Guru Sekolah Dasar, 1(1), 11-29. Retrieved from https://ummaspul.ejournal.id/MGR/article/view/325

Walgito,Bimo,(2004).PengantarPsikologi Umum, Andi Offset, Yogyakarta.

ZainalAbidinBaqir dkk,2006,Ilmu, Etikadan Agama, CRCS UGM,Yogyakarta.

Zamroni.1992.PengantarPengembanganTe oriSosial. Yogyakarta: Tiara Wacana. 